\title{
Discussion on the role of employee career planning in enterprise human
}

\section{resource management}

\author{
Tong Lei \\ College of Technology, HuBei Engineering University , Xiaogan, China , 432000
}

Key words: enterprise employees; career planning; human resources management; role

Abstract: with the development of knowledge economy, enterprises are facing more and more pressure of market competition. Human resource, as the key resource of enterprise development, has become the decisive factor of enterprise competition success or failure. Based on this, how to make use of employee's career planning and strengthen the effect of human resource management inside the enterprise has become an important project of internal management in our country. This article from the occupation career and the basic content of the occupation career planning, to explore the role of employee occupation career planning in the enterprise human resource management, and through the analysis, elaborated the relevant measures of enterprise human resources management.

\section{Career and career planning}

The occupation career is refers to the first time to participate in the work from the beginning of a person's life, engaged in a series of working practice and experience, usually we can according to the occupation type to describe occupation career, also can be recorded in accordance with the time line. Occupation career is a neutral word, does not have the meaning of success or failure, it is a society of social work in the social work summary, these contents can be full-time, can also be part-time, or even volunteer work.

Career planning is, in short, a systematic, systematic process of career and even life. Career planning is not only individual behavior, but also collective behavior. For an enterprise, as the main part of internal operation management, the career planning of employees is directly related to the sustainable development of individuals and enterprises. From a personal perspective, do the occupation career planning to set a predictable development goals for themselves, and increase their participation in the work enthusiasm, according to Maslow's hierarchy of needs, occupation career planning is the occupation through different levels to meet individual needs, and gradually realize self value. From the perspective of enterprise development, employee occupation career planning is an important part of human resource management, help the occupation development goals set by employees, to establish strict internal promotion mechanism, and incentive system, stimulate the enthusiasm of the employees involved in internal management, so as to provide sufficient power for the overall operation of enterprises[1].

In modern enterprise management, the factors that affect career planning include two aspects, namely personal and environmental factors. From the perspective of individual factors, employees in their own development needs, must make the appropriate expectations for their own occupation, there are many factors that influence the effect of personal occupation career planning, such as the individual's personality, strong positive, dare to struggle will be more scientific and rational 
employees for their own occupation planning compared with those who muddle along, the lazy people, although we often say "it is easy to change, being difficult to shift, but the ability and character of the individual will realize the change in the external environment under the intervention of the occupation career planning target will be adjusted accordingly; the occupation career stage, the career is the existence of a life cycle, for entry-level employees, the highly motivated, have great plans for their own occupation planning work for ten years, promotion It is stable, stable income of employees, the occupation planning is striving for retiring employees, the occupation career ended, so the enthusiasm of planning is not high. From the environmental factors, under the condition of market economy, national policies and regulations, market allocation of resources effect may become a factor affecting employee occupation career planning, but due to the employee's major work environment is mainly in the enterprise, therefore, the scale of the enterprise culture, management system, execution system, leadership qualities and core management personnel overall quality will have a direct impact on their occupation career planning[2].

From a philosophical perspective, the internal cause is the root cause of the development of things, but in the enterprise employee occupation career planning, enterprise as the main external environment, the external role is not to be underestimated, and even in some aspects of employee occupation career planning have a decisive effect, therefore, with the increasingly fierce market competition, the importance of talent in economic development gradually, enterprises should start from the perspective of human resources management, provide a favorable external environment for the employee's occupation career planning, so that employees can in the "people of the" environment, enhance the enthusiasm of the occupation career planning.

\section{The role of employee career planning in enterprise human resource management}

In modern enterprise management, human resource management has become an important content of internal management. In the traditional human resource management in the enterprise is more people as a kind of market investment and norms and constraints, minimizing personnel compensation expenses, and hope from the employees to obtain the biggest economic benefits. But from the rules of market economy, the "best" management style is not realistic, therefore, emphasize the modern human resources management theory, enterprise managers should take the human resource as a kind of resources, by building a good working environment, increase employee benefits, improve enterprise staff cohesion, is mining potential employees, really play the main way of talent value. In the enterprise resource management, employee occupation career planning is not individual behavior, a kind of internal management behavior, but is closely related with the development of enterprises so that enterprises should actively implement the corresponding measures of human resources management, improve employee occupation career planning department[3].

From the perspective of internal management, the role of employee career planning in the enterprise human resources management is mainly reflected in the following three aspects: first, it is conducive to promoting the harmonious development between employees and enterprises. In the fierce market competition, the enterprise wants to obtain the space of development must rely on the corresponding culture, incentive mechanism, supervision mechanism, evaluation mechanism, and the employee is involved in the main body of the enterprise internal management, the internal management system, and the concept of conformity, directly determines the occupation career planning science and not, as one of the employees do not agree with the concept of corporate culture, so their enthusiasm to participate in the management of natural difficult to mobilize, therefore, not to mention the cohesion of the enterprise. Based on this, enterprises in human 
resources management, according to the content of employee career planning to determine the reasonable level of internal management system, and then make targeted adjustments. Secondly, it provides a broader space for staff development. Occupation career planning target employee will be correspondingly adjusted with age, enterprise environment, self demand etc., enterprises through scientific human resources management measures can provide more reasonable elements for employee occupation career planning, such as the realization of self value in employees, enterprises can use the occupation training system, improve staff skills well, occupation ability, and provide the impetus for employees to update their occupation target. Finally, it is beneficial to improve the efficiency of resource allocation within the enterprise. Under the condition of market economy, talent as an important market resources, the allocation of benefits to a certain extent affect the enterprise long-term development planning, therefore, in the human resource management, enterprise can through screening, training, appointment, layoffs and so on employee occupation career planning is adjusted, it can not only stimulate positive the staff involved in the work of the internal management, ensure fair, rational allocation of enterprise resources to achieve development, improve management efficiency[4].

\section{The enterprise human resources management staff career planning related issues}

With the improvement of China's market economy, the importance of human resource management in the enterprise internal management is prominent gradually, and the use of effective human resources management measures, can improve the overall quality of talent market of our country, increase the market economic vitality. But there is always a gap between theory and practice, the human resources management of many enterprises still remain in the traditional mode, the neglect of the occupation career planning for employees, the potential value of employees is difficult to effectively play. At present, the personnel career planning in China's enterprise human resources management is mainly reflected in the following aspects: (1) lack of effective planning for the career of knowledge workers. Many enterprises in human resources management did not make special occupation career management of knowledge workers, just from the general staff management perspective on the work behavior for the corresponding standard, which makes a number of knowledge workers for the future development of enterprises lack of understanding, so naturally it is difficult to make a plan according to its own value in line with the objective actually, knowledge employee occupation career planning target blurred affects its enthusiasm in the internal management of enterprises, but also caused a waste of talent. (2) lack of hierarchy of career planning for employees is difficult to meet the long-term development requirements of enterprises. In the traditional human resources management, the enterprise usually use a unified management system for the deployment of personnel, promotion, no level of distinguished talents value in this mode of administration, general management seems to be fair, but inhibited the development of different levels of talent, can not meet the development requirements of enterprises, in addition to the in enterprise management, the employee occupation career planning unreasonable is often the existence of a number of both vocational situation, seriously restrict the development of the space of other levels of employees. (3) the salary mechanism of enterprise is unreasonable, so it is difficult to arouse the enthusiasm of employee career planning. Salary is a major consideration in employee career planning. In the enterprise human resources management, compensation and performance linked, but in the actual management, due to the slow pace of development, some enterprises for the employees, especially the knowledge workers usually can arrange some repetitive, secondary sexual content, which makes the staff's innovative thinking can not play effectively, the content of their work well, pay for performance is difficult to meet the needs of their own development, if things go 
on like this naturally lose the initiative occupation career planning[5].

\section{Strengthen employee career planning in the enterprise human resources management approach}

In the modern enterprise management, improve the effectiveness of human resources management, dig according to the potential value of talent has become the enterprise to obtain the competitive advantage of the "magic weapon", therefore, in market competition, enterprises should start from employee occupation career planning perspective, explore the effective strategy of human resources management, to maximize the realization of self value the space for the employees, and provide sufficient talents to promote the sustainable development of enterprises. In combination with the above problems, the ways to strengthen the career planning of enterprises in the management of human resources in enterprises can be expounded from the following points:

In the era of knowledge economy, enterprises want to achieve sustained and healthy development must rely on talent, especially the strong support of knowledge talent, so in the human resource management, the enterprise should provide education and training mechanism for talents and knowledge structure according to the modern enterprise development requirements constantly adjust the personnel, improve their professional skills, improve the overall competitiveness of enterprises; in addition, enterprises should also pay attention to the construction of internal culture, make clear enterprise development status and prospects for the development of staff, ensure the information become employee occupation career planning reference, so as to improve the internal management effect in enterprises and employees "win-win" goal.

Employee occupation career planning is not easy, it is a dynamic and systematic process, which relates to the goal and the content is complex, therefore, enterprises in human resources management, it should be from the common development of employees and the company's point of view, establish dynamic management strategy, on the one hand, according to the development strategy the requirements of the enterprise, and the occupation ability of employees, make scientific and rational deployment of personnel, in order to achieve the goal of resource allocation according to the evaluation system; on the other hand it should introduce the professional staff, personality, psychological quality, occupation ability, skill level and comprehensive assessment, scientific evaluation results guarantee efficient deployment of personnel.

For personal development, salary is not the only incentive, sometimes innovative work tasks are also an incentive for employees. In the innovative work, employees can not only get to play self innovative space, also can realize the ability of self-improvement in the work, and has a great sense of achievement and satisfaction, which is also in line with the needs of their self value realization. Based on this, the enterprise human resources management, should according to the employee's occupation ability, provide creative tasks for the knowledge workers, and provide some space for the rights of employees at work, to motivate employees to participate in the work of the[6].

Combined with the characteristics of employees, provide multiple career development path In the era of knowledge economy, the enterprise demand for knowledge talent gap is also gradually increased, and in order to attract more talents in the enterprise, in order to provide more scientific space occupation career planning, enterprises can according to the occupation development needs guide employees to achieve multiple occupation development plan, according to the characteristics such as occupation talents, provide part-time space for its employees, let to obtain full display. In addition, enterprises should also improve the internal management system, strengthen the employee occupation career planning management, the use of occupation evaluation system, the staff performance evaluation, to avoid blind expansion because the occupation development path, 
influence to carry out the work.

\section{Acknowledgement}

Fund program: Scientific Research Fund of Hu Bei Engineering University (201544)

\section{References:}

[1] Zhu Yafang. Employee occupation career planning in the enterprise human resources management research on [J]. in modern business, 2017, (05): 48-49.

[2] Wang Yan. The role of professional skill appraisal in the career management of enterprise employees [J]. times finance, 2013, (29): 209+216.

[3]Liu Xiangying. The application of psychological contract and career planning in the management of core employees [J]. human resources management, 2015, (10): 107-108.

[4]Hao Dongmei, Zhao Yu, Zhu Huanqing. Organizational career management and employee turnover intention: the mediating role of affective commitment [J]. Journal of Lanzhou University (SOCIAL SCIENCE EDITION), 2016,44 (01): 171-178.

[5] Li Y. Discussion on Employees' Career Planning of Mineral Resources Enterprise[J]. Science Mosaic, 2011.

[6]Triguero R, Peñavinces J C, Gonzálezrendon M, et al. Human Resource Management Practices Aimed at Seeking The Commitment of Employees on Financial and Non-Financial (Subjective) Performance in Spanish Firms: An Empirical Contribution[J]. Journal of Economics Finance \& Administrative Science, 2012, 17(32):19-26. 